\title{
Critical Success Factors influencing Web-Based Decision Support Systems in Online Shopping Context
}

\author{
Mohammed A. I. Ayoub \\ Limkokwing University of Creative Technology, Cyberjaya, Selangor, Malaysia \\ ayoub22265@hotmail.com
}

\begin{abstract}
Web-based decision support systems are increasingly used over the past years. However, few studies have been conducted on evaluation of web-based decision support systems especially in the field of online shopping. This paper attempts to explore the critical success factors that influence decision making satisfaction in online shopping context by providing a conceptual model for this purpose. Although there are various factors which contribute in making online shopping decisions but this study focuses on five factors i.e. web site quality, data quality, knowledge management, decision making satisfaction, and perceived net benefit. Also, this research will use existing models that explain and predict information systems success. However, these success models need to be updated to recurrent industry developments since the updating existing IS success models, a better understanding of web-based DSS practitioner success can be achieved.
\end{abstract}

Keywords: Critical success factors; Web-based decision support systems; Decision making satisfaction; Perceived net benefit; Online shopping

\section{Council for Innovative Research}

Peer Review Research Publishing System

Journal: International Journal of Management \& Information Technology

Vol. 8, No. 3

editor@cirworld.com

www.cirworld.com, member.cirworld.com 


\section{INTRODUCTION}

The usage of Internet has grown rapidly over the past years and it has become a common means for delivering and trading information, services and goods [1]. However, the web in particular and the Internet as a mother network became vital area to manage and develop the technical capabilities of decision support systems (DSS). Also, online shopping has become very popular in the last few years. There are many of online shops available all around the Internet, where Customers can purchase any commodity that they want as cars, books, electronics, jewelry, clothing and many other products while sitting comfortably at their home [2]. In the past, DSS applications have generally been implemented in commercial environments where users are employees of the firm. With the advent of web-based DSS, the user community is no longer limited to the managers and experts working on business-related problems, but beyond that to the ordinary users and customers [3]. Recently, the web has now become the platform of choice for building consumer DSS. According to Bharati \& Chaudhury, [3] DSS on the web has precipitated three major changes to the environment where DSS is being employed: a change in the user community, a change in problem domains, and a change in the underlying technology architecture. These changes in DSS have made it incumbent on the DSS researchers to reexamine the factors that influence efficacy and success of DSS in this new environment [3].

An example of a web-based DSS for customers is found at www.amazon.com, www.dell.com, www.overstock.com, www.myidaman.com, www.shopping.com, and www.tabo.ps and others, as online shopping websites, where customers can choose the kind of Commodity or service. These and other self-service information technologies that aid in decision-making are became quite prevalent. These web-based DSS are being used, but there is little research that has evaluated these systems from the perspective of users. Thus, more studies are needed that focuses on evaluating web-based DSS in online shopping context and exploring the critical factors influencing web-based DSS success in this field.

This paper investigate these web-based DSS, with a focus on factors that affect decision making satisfaction and in turn, perceived net benefit for customers, that is to say measuring the success of web-based DSS through decision making satisfaction and perceived net benefit in online shopping context. Although there are various factors which contribute in making purchase decisions but this study focuses on five factors i.e. web site quality, data quality, knowledge management, decision making satisfaction, and perceived net benefit. Also, this study used existing models that explain and predict information systems (IS) success as Wixom \& Watson, [4] and Delone \& McLean, [5]. However, these success models need to be updated to recurrent industry developments because by updating existing IS success models, a better understanding of web-based DSS practitioner success can be achieved.

This paper is organized as follows. Section 2 presents literature review. Section 3 presents related works. Section4 describes the conceptual model underlying the research. Finally, the conclusions of the study and suggestions for future research are presented in Section 5.

\section{LITERATURE REVIEW}

There is no doubt that DSS has evolved over the last decades, and is a general term about a wide set of Concerted technologies which aim to provide integrated support for managers working alone, in teams, and in organization to manage organizations and make more rational decisions. Recently, DSS have become a significant domain of IS research. The term DSS was first coined by Gorry \& Morton [6]. Over time a number of other definitions have been offered. Alter (1980) cited in [7], points out that a DSS can have many different forms and can be used in many different ways. According to Newman et al., [8], DSS are computer systems assist the user in complex problem solving or decision-making. Burstein \& Holsapple (2008) cited in [9] define the term of DSS as systems which represent and process information for the purpose of improving decision making. According to Pick, (2008) cited in [9] DSS can range in level of sophistication from a simple spreadsheet to sophisticated data warehousing and mining applications, knowledge management systems, or modeling systems. Sprague et al. (1982) cited in [7], define DSS as interactive computer-based systems that help decision makers utilize data and models to solve unstructured problems. A more specific definition is offered by Turban (1995) cited in [7], who defines a DSS as an interactive, flexible, and adaptable computer-based information system. According to Keen, (1980); Huber, (1982) \& Schroff, (1998) cited in [7], it is impossible to give a definition of DSS that covers all the aspects.

based on previous definitions of DSS and through a comprehensive survey of many of the definitions of DSS in the literature, the researcher concluded that there is no one single definition, Full, inclusive, generalizable, and agreed on by all researchers of DSS, but it is clear that there is consensus about the fact that DSS are computer-based systems that support management decision making and supports the consumers decisions who demand goods and services through internet stores. In other words, to support the buying decision.

\subsection{Web-Based DSS}

With the enormous development in the techniques of the Internet and the vast amount of information, data, and alternatives of various goods and services provided by Web sites, the concept of DSS In the development of a permanent, and became one of the most important types of DSS is web-based DSS.

According to Friedman, (2005) cited in [10] the importance of using web-based DSS originates from the growing amount of available information that should be identified, controlled and accessed remotely using web-based tools to support reusability of integrated decision modules where web-based systems are regarded as "platforms of choice" for delivering decision support. With the advent of web-based DSS, the user community expands to include, in addition to 
the managers and experts working on business-related problems, customers, suppliers and financers who shape the firm's policies and decisions [10]. According to Velmurugan \& Narayanasamy, [11], the term of web-based DSS is usually used to describe a computer based system designed to help decision makers use data, knowledge and communications technology to identify problems and make decisions to solve those problems.

\subsection{Online Shopping Decision Making}

The online Shopping Decision Making is act of purchasing products or services over the Internet, where the Internet provides quick and easy comparison of many different types of Products, searching for product information and buying goods online are becoming increasingly popular activities. According to Park, [12] online shopping is an activity in which consumers make a transaction to purchase products or services offered by online stores. According to Li \& Zhang, [13] Online shopping decision-making includes information seeking, comparison of alternatives, and choice making. According to Kollate \& Blackwell (1973) cited in [14] consumer decision making process consists five stages: problem recognition, search, alternatives evaluation, choice and outcome.

According to Sharkey et al., [15] selecting a product alternative is a multi-attribute decision process. Based on Waterfall diagram of decision process, the super-set, which contains all existing product alternatives, is the Universal Set, of course, the consumer may not be interested in all the alternatives in the set that sub-set of alternatives of which the consumer is aware, is the Awareness Set. All of the alternatives which the consumer proceeds to collect information about is called the Evoked Set and the set which the consumer evaluates further from the Evoked Set is called the Consideration Set, in turn, the choice is made from this final Consideration Set, see figure (1).

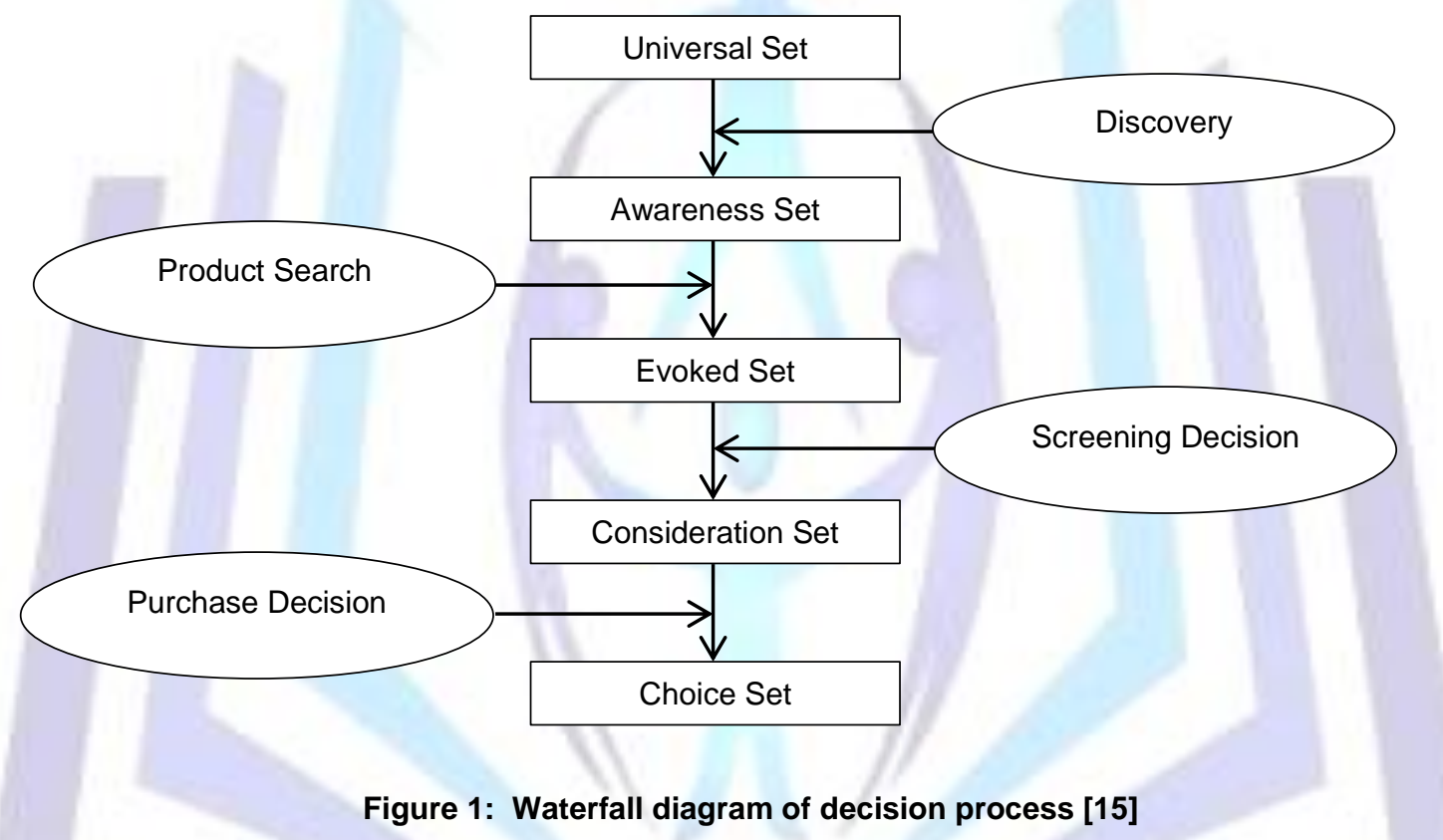

\section{RELATED WORKS}

The potential of DSS as computerized tools in assisting decision-making process has been attracting some researchers for the last years to improve decisions in online shopping. Most phases in online shopping involve crucial decisions that need to be made either by consumer or client [16].

In thesis for Johansson \& Gustafsson, [17] they has concentrated on building a cumulative theoretical framework of IS research applicable to the field of DSS, starting from Wixom \& Watson's research model from 2001. Via a multi method entailing the built up theoretical framework and two expert interviews a research model was designed, which subsequently was tested and evaluated through a survey in order find the answer to which critical success factors that significantly affects end users perceived net benefits as dependent variable for Measuring the success of a DSS postimplementation. By analyzing the survey result, this study identified three factors that significantly affect end users perceived net benefits, namely Data Quality, Problem Match and Support Quality. In addition, in this thesis was stated in the literature that System Quality should have a significant relationship with the dependent variable Perceived Net Benefits and this was not proven in their thesis context. However, the present study investigate the influence of some of these factors as data quality, website quality, in addition, knowledge management on decision making satisfaction and perceived net benefits to fit it with a field of this study.

According to Bharat \& Chaudhury, [3], and based on their research that endeavors to understand factors that impact decision-making satisfaction in web-based decision support systems. The information quality and system quality influence decision-making satisfaction. Their research has examined the perceptions of users on decision-making satisfaction and, in doing so, has validated part of the proposed model using the data. Based on their Recommendation, Further studies should also be conducted using other web-based DSS so as to test if the results of the present study can be extended to other situations. 
Santhanam et al., [18] in their study investigated Organizational DSS (ODSS) impact both at the individual and organizational level based on several ODSS currently in use. Their findings indicate that in order to have a successful ODSS, management must pay attention to individual user needs and also have several organizational level coordinating mechanisms in place. User participation, support of management, and DSS system characteristics were found to be important determinants of ODSS success. Success with individual DSS, Group DSS and networks has provided organizations the necessary expertise to build ODSS. While the progress in technology provides many capabilities for building ODSS, the success of these systems depends on other factors as well. Hence, practitioners will benefit from knowing the factors that could influence the successful impact of an ODSS.

The research results of Nosrati, [19] suggest that web site quality has a strong impact on satisfaction and also e-trust has a reasonable impact on quality and through quality affects satisfaction.

In paper for Garrity et al., [20], they examined Web-based information systems success and focused on User Satisfaction in the context of a consumer purchasing decision. In this paper they concluded that Decision Support Satisfaction plays an important role in Web-based information systems success. The results of this study, which draw on the DeLone and McLean, [21] Model the Garrity and Sanders, [22] model of IS success, and TAM, support the use of Web-based Information Systems Success Model for examining Web-based information systems success.

According to Zhang, [23] satisfaction is a key factor in online shopping, yet few of studies investigate it. Any number of factors, including vender/service/product characteristics, website quality, attitude towards online shopping, intention to online shopping, online shopping decision making, and online purchasing, may influence consumer's satisfaction. The relative importance of this factor in determining such consumer behavior as repeat purchases suggests that further research on consumer satisfaction with online shopping needs to be conducted.

According to Paul et al., [24] group members' satisfaction with system impacts the satisfaction with decision process and outcome. Satisfaction with decision outcome is also influenced by satisfaction with decision making process.

\section{CONCEPTUAL MODEL}

Based on the theoretical perspectives and related works, the following conceptual model is proposed, which incorporates concepts from earlier models to be applied to testing in the area of online shopping and other fields. This model is conceptually based on the IS success model Wixom \& Watson, [4] and DeLone \& McLean [5] which explains the impact of IS at the individual and organizational levels. The dependent constructs in the model is "decision making satisfaction and Perceived Net Benefit" and the independent constructs are: website quality, data quality, and Knowledge Management, see Figure (2).

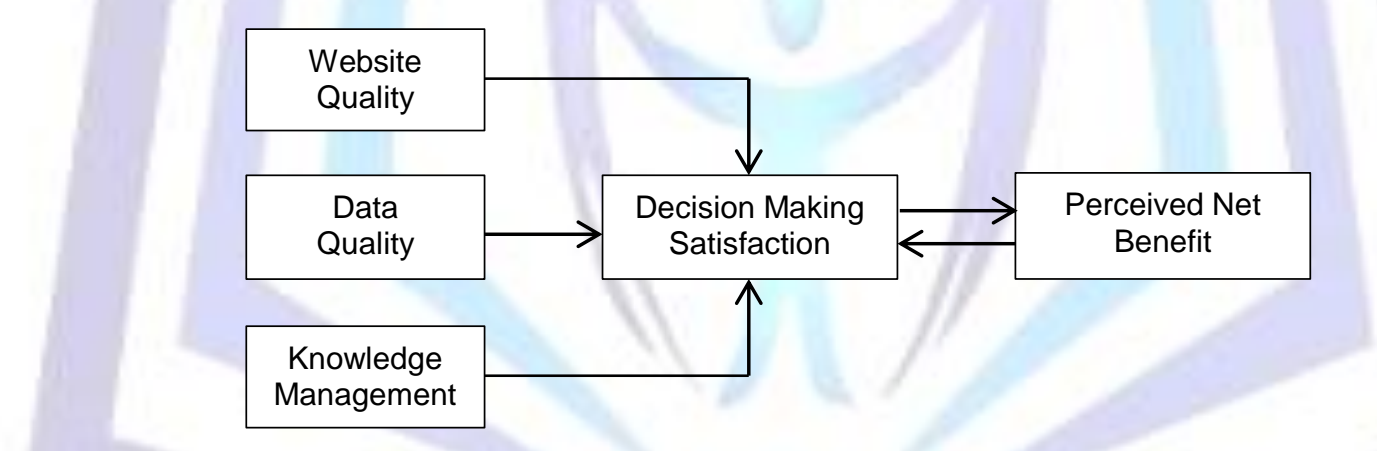

Figure 2: Proposed Conceptual Model

In this study, Web-Based DSS success in online shopping context is defined through decision-making satisfaction and perceived net benefit. Decision-making satisfaction is proposed to be determined by website quality, data quality, and knowledge management, in turn, decision-making satisfaction and perceived net benefit have mutual effect.

\subsection{Dependent variable: Perceived Net Benefit}

Net benefits refer to any and all outcomes that the IS causes to occur for the individual, the organization, or even the market. It has been very difficult to accurately target a single measure of net benefits. In the E-commerce environment in general and in online shopping especially, this task is not any easier. Different researchers have used completely different measures to operationalize the net benefits construct [25]. According to Seddon, [26] Perceived Net Benefit is defined as the sum of all future benefits less all future costs expected to flow from use of an information technology application.

As known, Net benefits added as new construct to the updated DeLone \& McLean [5] model. The construct includes and replaces two variables previously found in the DeLone \& McLean [21] model: individual impact and organizational impact. These are defined as the system impact on an individual (user) and organizational performance, respectively. According to Holley, [9] Critics of the model point out the Restriction of these two variables, arguing that the impacts of a system can span a wide range of stakeholders - consumers, work groups (e.g. [27]), industries (e.g. [28]), even 
society (e.g. [29]). Accordingly, the DeLone \& McLean [5] replace the two "impact constructs" with the more generic construct net benefits.

According to Delone \& McLean, [5] the impacts of IS have evolved beyond the immediate user, where some of researchers have suggested additional IS impact measures, such as work group impacts, Inter-organizational and industry impacts, consumer impacts, and societal impacts. Clearly, there is a continuum of ever-increasing entities, from individuals to national economic accounts, which could be affected by IS activity. The choice of where the impacts should be measured will depend on the system or systems being evaluated and their purposes. Rather than complicate the model with more success measures, Delone \& McLean Preferred to move in the opposite direction and group all the "impact" measures into a single impact or benefit category called "net benefits." Accordingly, in this paper, we adopted the net benefits as measurement Factor for web-based DSS success (dependent variable).

\subsection{Dependent variable: Decision Making Satisfaction}

Customer focus and satisfaction is a driving force for many companies and organizations. Measuring customer satisfaction provides an indication on how an organization is performing or providing products or services. Customer satisfaction has traditionally been studied within market research and the term customer satisfaction measurement is widely used in particularly business terminology. There are various definitions of customer satisfaction and to actually define satisfaction has proven to be hard and contradictory because of its multiple dimensions [30].

Customer satisfaction is generally understood as the satisfaction that a customer feels when comparing his preliminary expectations with the actual quality of the service or product acquired. In other words, customers are typically concerned with the value and quality of the product or service they receive. In addition, customers generally want the best possible product or service for a low cost [30]. According to Ives, (1983) cited in [24] Satisfaction of users with an IS is an effective measure of the success of the system.

Decision-making satisfaction scrutinizes the ability of a system to support decision-making and problem-solving activities [3]. Garrity, \& Sanders,[22] are clarify that the items in this construct determine whether the system supports the individual in recognizing problems, structuring problems, and making decisions related to the goal of controlling a business process.

In this paper, we explore critical success factors influencing decision making satisfaction with web-based DSS which refers to the contentment of the consumer with the particular DSS application used. It is noted that decision making satisfaction significantly correlated with perceived net benefit where the most important reasons for decision making satisfaction are to achieve some or all of the benefits that expected from the decision making. Also, Achievement of benefits and satisfy the desires will have the effect on decision making satisfaction. In other words, there is a mutual effect between decision making satisfaction and perceived net benefit. Accordingly, we will adopt decision making satisfaction as other measuring factor for web-based DSS success (dependent variable).

\subsection{Independent variable: Website Quality}

Many of studies investigate the relationship between website quality and consumers online shopping attitudes and behavior from different points of view, where the good designed website bring value and return on investment to webbased DSS. Web sites are generally the visible front-end to DSS in online shopping field, they are the gateways through which customers access Commodity, services will made available through web-based DSS. According to Li \& Zhang, [13] Better website quality can guide the consumer's complete transactions smoothly and attract them to revisit this Internet store. In contrast, worse quality would hinder their online shopping moves.

More recently, both e-business and e-commerce are increasing their demands for more online data analysis and decision support. The web platform, which is also a platform for e-commerce and online shopping field, lends itself to widespread use and adoption of DSS in organizations. According to Lociacono et al., [31] measuring Web site quality is an important concern for the areas of IS and marketing research.

\subsection{Independent variable: Data Quality}

Data quality has antecedents in the IS literature, widely used and argued in Large number of studies. DeLone \& McLean [21] builds their Information Quality factor on work dating back to 1949 based to communication theory. The information quality factor was originally built up and popularized by DeLone \& McLean [21]. Like the System Quality factor the Information Quality factor has widely been used within the IS success literature (Wang et al. 1995; Wand, 1996; Clark 2007, Wixom \& Todd 2005; Ramamurthy et al. 2007) cited in [17] indicating that it is not a specific factor only affecting Data Warehouse, thus, making it interesting in a model within online shopping area as our research area. According to Johansson \& Gustafsson [17] it is said by [29] that not all systems have the ability to produce information, thus, not making it possible to use this factor. This clear from the model that Wixom \& Watson [4] presents where that they have excluded the IS factor. Or rather changed it to Data Quality. Because the term Data Quality was more appropriate when discussing data warehouse system success and because the data warehouse is producing data rather than information.

Based on previous, we Integrated and merged Information Quality and Data Quality. So, we refer to this concept as Data Quality even though some authors denote it as Information Quality. According to Wixom \& Watson [4] the Data Quality factor had a significant impact on perceived net benefits and since the data quality variable was not data warehouse explicit we believed that the same result could be achieved in our research field. 


\subsection{Independent variables: Knowledge Management}

According to Fernandez et al., [32] the definitions of knowledge management (KM) range from the simple and straightforward doing what is needed to get the most out of knowledge resources. According to Woolf, [33] knowledge is organized information applicable to problem solving. According to Turban, [34] knowledge is information that has been organized and analyzed to make it understandable and applicable to problem solving or decision making; or, knowledge is reasoning about information and data to actively enable performance, problem-solving, decision-making, learning, and teaching.

Generally a knowledge management system is based on a particular domain of knowledge can be used to manipulate the domain knowledge to assist in the decision making process where $\mathrm{KM}$, it's truly a practice or discipline that involves people, processes and technology. And, if implemented correctly with cultural buy-in from users and customers, plus clearly defined goals, a KM initiative can improve the productivity and efficiency of decision making.

Often KM practices relating to service and support can be defined as knowledge-powered problem resolution - using a knowledge base, knowledge sharing, collaboration and knowledge reuse to efficiently solve customer questions [35]. Customers and end-users also benefit when they have direct access to a knowledge base to solve their own issues without ever contacting an agent [35]. KM has become an important theme as managers realize that much of their firm's value depends on ability to create and manage knowledge. To transform information into knowledge a firm must use additional resources to discover patterns, rules, and context where the knowledge works [36]; [37]; [38].

According to Grover and Davenport (2001) cited in [39] the online shopping companies who are able to process their information to turn it into knowledge and who manage their existing knowledge effectively will emerge as winners. The emergence of the Internet has also created a dynamic, electronic marketplace, where a new species of e-commerce organization is being established [40]. At the heart of the e-commerce organization is the website through which all the transactions take place. Besides supporting online transactions, a website can also give customers a means to obtain information about products and services [41] and companies the means to obtain information about their customers. With the growing importance of knowledge in e-commerce, one of the main purposes of a website is the ability to acquire knowledge by the both the customers and the organizations [42].

\section{CONCLUSIONS AND FUTURE RESEARCH}

The propositions presented in this paper an opportunity for further investigation in the web-based DSS evaluation with focus on critical success factors influencing Web-Based DSS in Online Shopping Context.

The proposed model should be of interest to IS practitioners in general and DSS practitioners in particular and academic community. For the practitioner community, the model will enhance their understandings on the factors that contribute of DSS success and enlighten DSS-vendors about what parts of the post-implementation phase they should concentrate on to increase the success of the system and end users decision making satisfaction. For the academic community, the proposed model provides ample research opportunity to validate in order to support or refute the proposed propositions.

We recommend other researchers for the work of empirical study on the proposed model in communities that have a weakness in the field of online shopping to measure the success of web-based DSS in the field of online shopping Also, to know and anticipate the factors that affect the acceptance of online shopping idea by citizen's especially in countries that in initiative stage of construction and implementation of online shopping systems.

\section{REFERENCES}

[1] Delafrooz, N. 2009. Factors Affecting Students' Online Shopping Attitude and Purchase Intention. University Putra Malaysia.

[2] Janik, M. 2007. Online Shop Web Tier in Java EE. Masaryk University. Faculty of Informatics.

[3] Bharati, B., \& Chaudhury, A. 2004. An empirical investigation of decision-making satisfaction in web-based decision support systems, University of Massachusetts, Boston, MA, USA.

[4] Wixom, B. H., \& Watson, H. J. 2001. An Empirical Investigation of the Factors Affecting Data Warehousing Success, MIS Quarterly, 25(1), 17-41.

[5] DeLone, W. H., \& McLean, E. R. 2003. The DeLone \& McLean Model of information system success: A TenYear Update. Journal of Management Information System, 19(4), 9-30.

[6] Gorry, G. A., \& Scott-Morton, M. S. 1971. A Framework for Information Systems, Sloan Management Review, 13, 1, 56-79.

[7] Kwakkel, J. H. 2006. DSS failure studied from an adaptive design perspective, Delft University of Technology.

[8] Newman, S., Lynch, T., \& Plummer, A. A. 2000. Success and failure of decision support systems: Learning as we go, Central Queensland University, North Rockhampton, and Queensland 4702 Australia.

[9] Holley, M. R. 2011. Decision Support Systems and Financial Risk Assessment An evaluative study, Lund University. 
[10] Gasmelseid, T. M. 2006. Multi agent Web based Decision Support Systems for Global Enterprises: An Architectural Blueprint, Department of Information Systems, College of Computer Sciences and IT, King Faisal University.

[11] Velmurugan, M. S., \& Narayanasamy, K. 2008. Application of Decision Support System in E-commerce," Multimedia University, Melaka, Malaysia.

[12] Park, Y. A. 2007. Investigating Online Decision-Making Styles, Texas A\&M University.

[13] Li, N., \& zhang, P. 2002. Consumer Online Shopping Attitudes and Behavior: An Assessment of Research, Eighth Americas Conference on Information Systems, Syracuse University.

[14] Zhang, J. L. 2011. An Empirical Analysis of Online Shopping Adoption in China, Lincoln University, Canterbury, New Zealand.

[15] Sharkey, U., Acton, T., \& Conboy, K. 2009. Modeling the Effects of Decision Tools in Online Shopping, 22nd Bled e-Conference, e-Enablement: Facilitating an Open, Effective and Representative e-Society, June 14 17, Bled, Slovenia.

[16] Mohemad, R., Hamdan, A. R., Othman, Z. A., \& Noor, N. M. M. 2010. Decision Support Systems (DSS) in Construction Tendering Processes, Selangor, Malaysia.

[17] Johansson, J., \& Gustafsson, B. 2009. Critical Success Factors affecting Decision Support System Success, from an end-user perspective, Department of Informatics, Lund University.

[18] Santhanam, R., Guimaraes, T., \& George, J. F. 2000. An Empirical Investigation of ODSS Impact on Individuals and Organizations, USA.

[19] Nosrati, L. 2008. The Impact of Website Quality on Customer Satisfaction - A Research on Iranian Online Bookstores," Lulea University of Technology.

[20] Garrity, E. J., Glassberg, B., Kim, Y. J., Sanders, L., \& Shin, S. K. 2004. An experimental investigation of Web-based information systems success in the context of electronic commerce, New York 14260, United States.

[21] DeLone, W. H., \& McLean, E. R. 1992. Information system Success: The quest for dependent variable, Information system research $3: 1$.

[22] Garrity, E. J., \& Sanders, L. 1998. Dimensions of information systems success, in: E.J. Garrity, G.L. Sanders (Eds.), Information Systems Success Measurement, Idea Group Publishing, Hershey, PA, pp. 13- 45.

[23] zhang, N. L. P. 2002. Consumer Online Shopping Attitudes and Behavior: An Assessment of Research, syracuse university.

[24] Paul, S., Seetharaman, P., \& Ramamurthy, K. 2004. User Satisfaction with System, Decision Process, and Outcome in GDSS Based Meeting: An Experimental Investigation, Proceedings of the 37th Hawail International Conference on System Sciences.

[25] Perez-Mira, B. 2010. Validity of Delone and Mclean's Model of Information Systems Success at the Web Site Level of Analysis, The E.J. Ourso College of Business Information Systems and Decision Sciences.

[26] Seddon, P. 1995. Perceived Net Benefit as a Measure of IS Success and Predictor of IS Use, (ICIS) International Conference on Information Systems, Proceedings, http://aisel.aisnet.org/icis1995/37.

[27] Ishman, M. 1998. Measuring information system success at the individual level in cross-cultural environments, In E. Garrity, L. Sanders, eds (1998): Information Systems Success Measurement. Idea Group, Hershey, PA.

[28] Clemons, E., Reddi, S., \& Row, M. 1993. The Impact of Information Technology on the Organization of economic Activity: The move to the middle hypothesis," Journal of Management Information Systems Vol 10 No 2 pp 9-35.

[29] Seddon, P. 1997. A Specification and extension of the DeLone and McLean Model of IS Success, Information Systems Research Vol 8 No 3 pp 240-253.

[30] Lodenius, E. 2011. Customer Satisfaction Measurement within the Road Sector - further development of customer feedback systems and a public input model, Department of Civil and Environmental Engineering, Aalto University's.

[31] Lociacono, E., Watson, R. T., \& Goodhue, D. 2000. Web Quall Tm: A Web Site Quality Instrument, Working Paper. Worcester Polytechnic Institute.

[32] Fernandez, A., Gonzalez, R., \& Sabherwal, 2004. Knowledge Management Challenges, Solutions, and Technologies, Pearson/Prentice Hall, Upper Saddle River, NJ.

[33] Woolf, H. 1990. Webster's New World Dictionary of the American Language, G. and C. Merrian. 
[34] Turban, E. 1992. Expert Systems and Applied Artificial Intelligence, Macmillan.

[35] Tobin, T. 2003. Ten Principles for Knowledge Management Success, Director, Business Consulting Knova Software, Inc.

[36] Supyuenyong, V., \& Islam, N. 2006. Knowledge Management Architecture: Building Blocks and Their Relationships, Technology Management for the Global Future, Vol. 3, pp. 1210-1219.

[37] Laudon, K. C., \& Laudon, J. P. 2006. Management Information Systems. Managing the Digital Farm, Prentice Hall, pp. 428-508.

[38] McLeod, R., \& Schell, G. 2006. Management Information Systems, 10th Edition, Prentice Hall, pp. $250-274$.

[39] Maswera, T., Dawson, R., \& Edwards, J. 2006. Assessing the Levels of Knowledge Transfer within eCommerce Websites of Tourist Organizations in Africa, The Electronic Journal of Knowledge Management Volume 4 Issue 1, pp 59-66.

[40] Singh, N., \& Kundu, S. 2002. Explaining the growth of E-commerce corporations (ECCs): An extension and application of the eclectic paradigm, Journal of International Business Studies, Vol. 33, Iss. 4, pp 679-697.

[41] Kohavi, R. 2001. Mining E-Commerce Data: The Good, the Bad and the Ugly, Proceedings of the 7th ACM SIGKDD International Conference on Knowledge Discovery and Data Mining, San Francisco, USA, pp. 8-13.

[42] Fang, S., \& Holsapple, C. W. 2003. The Usability of Websites for Knowledge Acquisition: A Taxonomy of Influences, International Journal of Electronic Business, Vol. 1, No. 2, pp 211-224. 